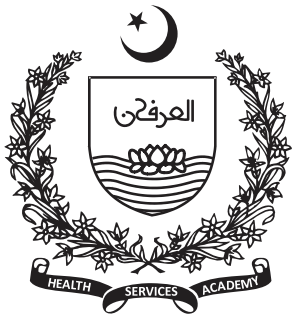

Institute of Health Management-Dow University of Health Sciences

\section{An Ecological Study: The Causations, Consequences, and Combatants of Malnourishment in Sub Sahara Africa}

\author{
Hira Maqsood
}

\section{Abstract}

Background: The study expatiates major causation and consequences of malnourishment in Sub Sahara Africa and concurrently explores the efficacy of salubrious nutriment effectual in complying health requisite of indigent populaces.

Methods: An ecological study circumscribes about underprivilege African territories enduring deplorable conditions and health-related challenges. Selects twenty States resides in Sub Sahara Africa, employing nonrandom nonproportional quota sampling, each reveal critically on considered causations and consequences of malnourishment. Followingly delve efficacy of combatant of malnourishment, by contrasting five North African Territories, each chief producer of healthy nutriment, against the rest of Africa. All considered variables characterizing causation, consequences, and combatant assessed inconsideration to malnourishment. Study articulated considering primary and secondary sources available online. Perform statistical analysis using SPSS 16. Complete compilation phase lasts for four months extend from June to September 2019.

Results: Populace internal and external mal exposure characterizing undernutrition proportion, adulterated water consumption, poor sanitation, ambience aerial perils, vehement UV-radiations, noise nuisance, constitute major causation of malnourishment in children under age 5. Subsequently, high proportion of childhood stunting or wasting determines negative correlation with adulthood intelligence quotient, productivity, and healthy life span. Whereas nations enrich in healthy nutriments embracing dates, honey or olive oil considerably precludes malnourishment, encounter relatively low incidence of stunting and wasting.

Conclusion: Insalubrious internal and external mal exposures considerably reprehensible for continuous acclivity in prevalence of malnourishment. Increase incidence in early ages impel health diminution in later phases of life. Incorporation of healthy regimen likely to halt grueling trends and execute populace healthy profiles.

Keywords: Stunting; wasting, causation; consequences; combatant; Children under-age 5 


\section{Introduction}

$\mathrm{M}$ alnourishment characterizing stunting and wasting is inordinately servile to internal and external insalubrious exposures, reprehensible for inadequate nurture and nourishment, impels increase vulnerability to various physical, psychological, and physiological disarrays (1). Stunting and wasting encounter in early age is excessively subservient to degenerative health status and relatively shorter life span.

According to the global nutrition report 2017, approximately 151 million children of age under 5 suffers from stunting while 50 million onerous of wasting and both aggregately account for 15.95 million children around the world. (1) Sub Sahara Africa with no significant progress continues to endure grueling trends in the prevalence of malnourishment, $39 \%$ of stunting, and $25 \%$ of wasting.

(1) Whereas Asia seems to observe slight control over the situation with the incorporation of appropriate measures.

Today malnourishment is a global threat, afflicts a large proportion of the populace worldwide. Convicting $8 \%$ of the world populace including $15 \%$ of stunting and $6 \%$ of wasting. (1)

The WHO and UNICEF aim to subside stunting by $40 \%$ and wasting below $5 \%$ by 2025 , with increased emphasis on the adequacy of sustenance, salubrity, and sanitation. (1)

The study expatiates causations and consequences of malnourishment concomitantly explore the efficacy of salubrious nutriments effectual in complying health requisite of the indigent populace.

\section{Methodology}

An ecological study circumscribes about underprivilege African territories enduring deplorable conditions, and health-related challenges.

The study encompasses twenty States residing in Sub Sahara Africa (East, Middle, West). Selected employing nonrandom nonproportional quota sampling. Each State selected reveal critically on considered causations and consequences of malnourishment. Also, priority is given to ease of data accessibility and availability.

Initially depicts subsistence in underprivilege landmasses by observing each selected State on considered variables embracing populace undernutrition proportion (scale as $1={ }^{\prime}<10 \%$ ', $2=$ ' 11 to $15 \%$ ', $3=$ ' 16 to $20 \%{ }^{\prime}, 4==^{\prime}>20 \%$ ')(1), availability of clean drinking water sources $\left(1={ }^{\prime}>85 \%\right.$ ', $2=$ '76 to $85 \%$ ', $3=$ ' 66 to $75 \%$ ', $4==^{\prime}<65 \%$ ') (2), incorporated general sanitation $\left(1={ }^{\prime}>75 \%\right.$ ', $2={ }^{\prime} 66$ to $75 \%$ ', $3={ }^{\prime} 56$ to $55 \%$ ', $4==^{\prime}<55 \%$ ')(2) concentration of ambience aerial perils $\left(1={ }^{\prime}<20 \%\right.$ ', $2=$ '21 to $30 \%$ ', $3=$ '31 to $40 \%$ ', 4 $\left.=^{\prime}>40 \%{ }^{\prime}\right)(3)$, mean annual UV index $\left(1={ }^{\prime}<5^{\prime}, 2={ }^{\prime} 6\right.$ to $8^{\prime}, 3={ }^{\prime} 9$ to $\left.11^{\prime}, 4==^{\prime} 12^{\prime}\right) \quad$ (4) and noise pollution(estimated using perception index, population density per km sq., family sizes). $(3,5)$ Each considered variable juxtaposes categorization on 1 to 4 scale, incompliance to respective standard dictations by authorizing bodies. Briefly reveals populace ingestion, imbibes, interfaces, inhabitations considered causation of malnourishment. And followingly group three major causation for each internal and external mal-exposure employing factor analysis.

Further, proceed by calculation of multiple correlation coefficient for both stunting and wasting discretely against intelligence (IQ score), (6) industriousness (GNI per capita/average weekly work hours) $(3,7)$, and salubrity (Healthy life expectancy) (8) delineating consequences of malnourishment.

Finally determines the efficacy of salutary nutriments effectual in complying health requisites and assurance of salubrity among masses, by contrasting five North African territories (Egypt, Algeria, Tunisia, Morocco, Libya), each chief producer of dates, honey, or olive oil, on malnourishment against rest of Africa.

All the considered variables characterizing causation, consequences, and combatant assessed inconsideration to childhood malnourishment, including stunting or wasting.

The study articulated considering primary and secondary sources available online. Derive most figurative data, used in conducting analysis and drawing inferences, mainly of FAO, UNICEF, WHO, $(1,2)$ The World Bank (3). Whereas PubMed, DOAJ, Google Search excessively browse to excerpt relevant secondary content. Perform all computations on SPSS 16. The complete compilation phase lasts for 4 months dates June to September 2019.

Thus, the study tends to address the following research objectives.

State major causations and consequences of malnourishment? State efficacy of salubrious combatants against malnourishment? 
Table 1: Causation of Malnourishment

\begin{tabular}{l|c|c|cc}
\hline \multicolumn{3}{c}{ Extraction Method: Principal Component Analysis. } \\
\hline \multicolumn{1}{c|}{ Causations } & Initial & Extraction & \multicolumn{2}{c}{$\begin{array}{c}\text { Extracted } \\
\text { Components }\end{array}$} \\
\hline Population & 1 & 0.58 & 0.71 & -0.27 \\
Undernutrition & 1 & & & \\
Proportion & 1 & 0.79 & 0.89 & 0.09 \\
Clean Drinking & 1 & 0.77 & 0.84 & 0.27 \\
Water Accessibility & 1 & 0.40 & -0.45 & 0.44 \\
General Sanitation & 1 & 0.71 & 0.21 & 0.82 \\
Air Pollution & 1 & 0.61 & -0.11 & 0.77 \\
Mean Annual UV & & & 2.24 & 1.62 \\
Index & & & 37.38 & 27.03 \\
\hline Noise Nuisance & & & & \\
\hline Initial Eigenvalues & & & & \\
\hline \% of Variance & & & & \\
\hline
\end{tabular}

Source: The State of Food Security and Nutrition in the World 2018*, Progress on household drinking water, sanitation and hygiene 2000-2017, *, The World Bank,2018*, Weather-Atlas,2019*, Nation Master,2013*

\section{Result}

The study derives 2 major factors, performing the factor analysis namely external and internal malexposures, each constitutes 3 pertinent components enduring high loading.

Internal exposure embracing undernutrition proportion, clean water accessibility, general sanitation while ambiance aerial perils, UV index, noise nuisance attribute external exposure, both in combination characterizes mal-exposure, constitute deplorable conditions for landmasses and instigate detrimental health challenges. (Table 1)

Insalubrious external and internal exposure, the two major propellers respectively responsible for $37 \%$ and $27 \%$ of the variance, strongly determines the escalated trends of malnourishment among the populace. (Table 1)

The persistence of mal-exposure considerably signifies a high prevalence of stunting and wasting in early childhood reprehensible for undermining psychological, physiological, and physical capacity in later stages of life. Calculation of multiple correlation coefficient manifests a high proportion of each childhood stunting( $R=0.62)$ or wasting $(R=0.66)$ impel low adulthood productivity, proficiency, and prosperity. Further, corroborate by computation of $\mathrm{F}$ statistics, 5.4 and 6.7, of stunting and wasting, tends to be greater than $3.49(\mathrm{df}=17, \mathrm{p}<0.05)$. (Table 2) Hence, populace laden with figures of growth impairment often lags in intellects, industriousness, and salubrity. Also, childhood stunting or wasting increases vulnerability to various acute and chronic diseases likely to confine life span. Proportion likely to execute shorter life expectancies.

On the other hand, healthy nutriment bearing high nutritional value, requisite of rudimentary integrals, easily proliferate in most geographical locations and specifically, favor regions situated near the equator can be effectual combatant against malnourishment for the populace residing on underprivilege landmasses. Elucidated by the graphical plot of five north African territories, eminent in the production of dates, honey, and olive oil, likely to be less onerous with malnourishment than other African territories. (Figure 1)

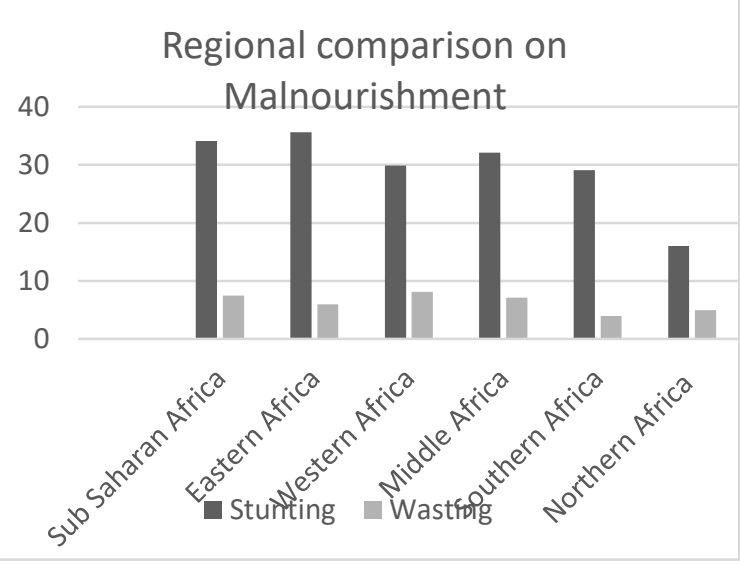

Figure 1

Table 2: Consequences of Malnourishment.

\begin{tabular}{llllll}
\hline & & & & & \\
Selected States & $\begin{array}{l}\text { Stun } \\
\text { ting }\end{array}$ & $\begin{array}{l}\text { Wasti } \\
\text { ng }\end{array}$ & $\begin{array}{l}\text { Intell } \\
\text { gence }\end{array}$ & $\begin{array}{l}\text { Industri } \\
\text { ousness }\end{array}$ & Salubrity \\
\hline Benin & 34 & 5 & 70 & 22 & 53 \\
Burkina Faso & 27 & 8 & 68 & 17 & 53 \\
Burundi & 58 & 6 & 69 & 7 & 53 \\
Cameroon & 32 & 5 & 64 & 36 & 51 \\
Central African & 41 & 7 & 71 & 9 & 45 \\
Republic & 40 & 13 & 68 & 17 & 47 \\
Chad & 38 & 10 & 69 & 16 & 58 \\
Ethiopia & 25 & 11 & 66 & 17 & 54 \\
Gambia & & & & & \\
\end{tabular}




\begin{tabular}{llllll} 
Guinea & 32 & 8 & 67 & 17 & 52 \\
Liberia & 32 & 6 & 67 & 13 & 55 \\
Madagascar & 49 & 15 & 82 & 11 & 58 \\
Mozambique & 43 & 6 & 64 & 11 & 52 \\
Niger & 42 & 10 & 69 & 10 & 53 \\
Senegal & 17 & 7 & 76 & 35 & 59 \\
Somalia & 25 & 15 & 68 & 4 & 50 \\
Tanzania & 34 & 5 & 72 & 23 & 57 \\
Togo & 28 & 7 & 70 & 16 & 54 \\
Uganda & 29 & 4 & 84 & 16 & 55 \\
Zambia & 40 & 6 & 79 & 30 & 54 \\
Zimbabwe & 27 & 3 & 82 & 45 & 54 \\
\hline
\end{tabular}

\begin{tabular}{|c|c|c|c|}
\hline \multicolumn{4}{|c|}{ Statistical Analysis } \\
\hline Stunting & & & \\
\hline $\begin{array}{l}\text { Correlation } \\
\text { Coefficient (r) } \\
\text { Multiple } \\
\text { Correlation } \\
\text { Coefficient }\end{array}$ & $R=62 \%$ & $\begin{array}{l}F=5.4, \quad \text { Critical value of } \\
f=3.59, \quad d f=17, p<0.05\end{array}$ & -0.45 \\
\hline Wasting & & & \\
\hline $\begin{array}{l}\text { Correlation } \\
\text { Coefficient (r) } \\
\text { Multiple } \\
\text { Correlation } \\
\text { Coefficient }\end{array}$ & $R=66 \%$ & $\begin{array}{l}\mathrm{F}=6.7, \quad \text { Critical value } \\
\mathrm{df}=17, \mathrm{p}<0.05\end{array}$ & $f=3.59$ \\
\hline
\end{tabular}

Source: The State of Food Security and Nutrition in the World 2018*, The World Bank, 2018*, Nation Master,2013*, World Life Expectancy ,2017*

\section{Discussion}

Malnourishment briefly encompassing stunting and wasting, characterizes physical, physiological impairment or simply dimensional inhibition. Malnourishment is a rising threat globally, inflicting a large proportion of the populace charging \$35 trillion of health expenditure annually. (9) It is conspicuously eminent in low and low middle-income states, and compellingly existential in rural than urban territories. (9)

Stunting and wasting tend to be co-existential, usually encounter in early phases of life, measure by assessing height against age and weight against height, respectively. Ranges depicting severity index for the populace define stunting less than $10 \%$ low, 10 to $20 \%$ moderate, and above $20 \%$ high. (10) Similarly, the prevalence of wasting categorizes as less than $5 \%$ low, 5 to $10 \%$ moderate, and greater than $10 \%$ high. Incompliance to define ranges $36 \%$ world States stands low, 30\% moderate, and $74 \%$ high on the stunting index while 33\% States low, 39\% medium, and 24\% high on the wasting index. (10)
According to a global nutrition report, Africa endures the exasperating trends in the prevalence of stunting, reports an increase from \$ 50.6 million in 2000 to $\$ 58.7$ million in 2017. More than half of the children in Eritrea, Nigeria, Burundi bummer of stunting. The continent abides a significant proportion of wasting, threatening the life of 13.8 million children under age 5. (1) Whereas estimated prevalence in northern (including Sudan) and western Africa also considerably high $8.5 \%$ and $7.9 \%$, respectively. (1)

Nutritional ingestion and imbibes characterizing an adequate proportion of carbohydrates, fats, proteins, vitamins, and minerals, integral for appropriate nurture and nourishment. Children under 5 dietary intakes should ensure $0.18 n$ richment in fats (30-35) \%, protein (1.1-1.2) g/ kg, energy (90-100) kcal/kg, Vit D (5) ug. (11)

Unavailability and inaccessibility to enough dietary intakes often engender sustenance, impels the prevalence of starvation characterizing impoverish 0.1 masses. According to the global nutrition index States, comprised of 35 to $50 \%$ of the undernourished populace indicate extreme severity index, 20-35\% high, $10-20 \%$ slight, and below $10 \%$ less severe. (12) The sustenance development goal dictates for zero hunger by addressing the issues of food safety and sufficiency (1).

Globally the prevalence of undernutrition has risen by $11 \%$, from 775 million in 2015 to 815 million in 2016. Significant figures observe in Africa (20\%) following Asia (11.7\%) Oceania (6.8\%), Latin America, and the Caribbean (6.6\%). (1) Northern Africa excluding Sudan reveals 5\% of starvation. The alarming situation in Sub Saharan Africa, extreme food insecurity convicting $22.7 \%$ of the populace. Corroboration of famine in South Sudan whereas Nigeria, Somalia, and Yemen closely border. Every one-third of the populace in eastern Africa appears to be undernourished. (1)

Inadequate consumption of nutrition essential for metabolic regulation convoke for physiological adjustment to ensure the functionality of vital organs and systems. As a result, lead to muscle mass erosion and skeleton growth retardation. (13)

Research findings in the past reveal a high proportion of stunting $(24.9 \%)$ and wasting $(11.1 \%)$ in individuals bearing a high index of undernutrition. (14) Growth faltering excessively ensues of deficiency, of iodine, and zinc concentration in children's dietary intake. (15) 
Moreover, based on the millennium development goal, $88 \%$ of the population should have accessibility to clean drinking water for a healthy society. (16) Pure drinking water determines by $\mathrm{pH}$ value between 6.8 to 8 , the absence of fecal coliform bacteria, and appropriate concentration of chemical constituents embracing ammonia, chloride, iron, lead, copper, arsenic. (17) Water quality indices falling within the range of 95-100, 80-94, 65-79, 44-64 accordingly designates excellent, good, fair, and poorquality status. (17)

Globally $71 \%$ of the populace ensures access to safe drinking water, embodying $85 \%$ of urban and $53 \%$ of rural populace. (2) A significant proportion of Egypt, Algeria, Tunisia, Morocco, Libya execute coverage to unadulterated drinking water. (2)

Inaccessibility to clean water threatens the sustainability of a large proportion of the world populace. Approximately 785 million people around the world lack access to safe drinking water. (2) 144 million people worldwide still depend on the surface water of which two-third resides in Sub Sahara Africa. (2) Trends in central Asia and eastern Africa considerably dreadful almost 39\% of Sub Sahara Africa relies on contaminated water sources. (2)

The finding indicates the consumption of contaminated water induce wasting. Based on a review article of $48 \%$ of studies, clean water accessibility dissociates the occurrence of stunting. (18) Reliance's on pure drinking water facilitates an increase in height among children under age 5. (19)

For subsistence, in addition to enough ingestion and imbibes, the populace should exercise general hygiene. The state should accommodate a minimum of $77 \%$ of the populace with basic sanitation facilities, (16) characterize by basic infrastructure appropriate for human waste disposal, to comply with MDG.

About $45 \%$ of the total world populace exhibit sanitation facility, including $48 \%$ of urban and $43 \%$ of rural residents. (2) Only $34 \%$ of the population with accessibility resides in the least developing states. (2)

Globally 2 billion people lack basic sanitation facilities, around 673 million exercise open defecation, with every 9 of 10 in rural regions. 22\% mark with the unavailability of water or soap and $18 \%$ without any facility within premises. (2)

Figures for Sub Sahara Africa further aggravated, execute less than $50 \%$ coverage to basic sanitation facilities, continue to increase the use of unimproved or shared facilities, open defecation still exercises by 709 million people. (2)

Poor sanitation services or sewerage infrastructure are major contributors to childhood stunting and wasting. According to a comprehensive review, $70.6 \%$ of studies manifest incorporation of appropriate sanitation precludes stunting. Home equipped with an attached bathroom reduces susceptibility to linear impairment. Every $10 \%$ rise in open defecation comrade $0.7 \%$ increase in growth inhibition. (18) $22 \%$ of studies conclude the administration of hygienic household ambiance inhibits early childhood growth challenges. (16)

Moving on to external exposures, the concentration of particulate matter deeply contingents on humanoid domestic to occupational activities. Acceptable figures for short term and long-term particulate matter mean annual exposure dictated by $\mathrm{WHO}$ are $10 \mathrm{Ug} / \mathrm{m} 3$ and $25 \mathrm{Ug} / \mathrm{m} 3$, respectively. (20) Finding reveals mean annual exposure to aerial perils, indexing between $11-15 \mathrm{Ug} / \mathrm{m} 3$ is incipient to health diminution, indexing beyond is susceptible to detrimental repercussions. (20)

Globally $93 \%$ of children are frequently exposed to ambient air pollution. Embodying 630 million children age below 5, of which $98 \%$ belong to humble and indigent nations. (21)

The substantive review suggests air pollution exposure significantly causes malnourishment, 8 studies report lead exposure at pre, and post-natal phases impel height retardation, 6 studies confirm the negative influence of tobacco exposure on child growth. Exposure to indoor pollutants ensues a 30\% increase in vulnerability to stunting. (18) Air pollution exposure for 2-year comrades $0.6 \mathrm{~cm}$ reduce height in early childhood. (19) While one study connotes an association between Vit D, the growth regulator, and air pollution. (18) By elucidating the phenomena of air pollutants impeding UV radiation from reaching the earth's surface, subsequently leading to increasing sufferance of Vit D deficiency because of low solar exposure.

UV index characterizes by solar radiation exposure are submissive to various acute and chronic health issues. UV indices usually range between 1 to 12 , consider less noxious below or tantamount to 5 while rising above proportionately hazardous. (22) States residing in the northern hemisphere endure low UV index while states residing close to the equator experience extreme. UV index usually values between 
10 to 12 in most African territories and lasts for 8 to 10 months. (4)

Vit D, the derivative of solar exposure, execute immunity against various benign and malignant disease, fatal and non-fatal infection. Africans are likely to be more Vit $\mathrm{D}$ deficient due to deep pigmentation mark by a high concentration of melanin reprehensible for depleted levels.

Deficiency of Vit D impel dimensional impairment. A study conducted in South Africa reports a strong relation between Vit D concentration and height retardation in early childhood. (23) Another finding reveals $18.6 \%$ of children with serum 25(OH)D level below $42.5 \mathrm{nmol} / 1$ found to be stunted. (23) One study manifest $51 \%$ of malnourished children likely to be a deficit of Vit D, reporting serum 25(OH)D between $32.5 \pm 12.0 \mathrm{mg} / \mathrm{ml}$. (24) Also, Vit D deficiency accounts for poor immunity increase susceptibility to infectious disease, and inducing muscle wasting. (25)

WHO delineates noise by the sound pitch between 55 to $65 \mathrm{~dB}$. And consider prolong noise exposure, excessively ensues of domestic activities and occupational engagements, deterrence to populace wellbeing while a range of 65 to $70 \mathrm{~dB}$ or above an inducement to hearing impairment. (26)

A large proportion of the world populace experience noise nuisance in daily life. Also, underprivileged regions of Africa stand intense on the noise pollution index. Limited work has been contributed to exploring the deleterious effect of noise on health. A study finds the effect of noise pollution among two groups of residents, one residing close to the airport while others at a distant. Reveal, high-level Epinephrine, a stress component instigates growth inhibition, among the exposed group. Thus, corroborates the correlation between growth impairment and noise nuisance. (27)

The consequences of malnourishment encounter at an early age are explicitly evident in the later phase of life. Increasingly reprehensible for compromise cognitive, caliber, capacitive capabilities, poor immunity against a host of disease, irregularity of food ingestion, digestion, assimilation, dysfunctionality of vital organs and systems, inappropriate muscular and skeletal configuration. Thus, individuals afflicted with malnourishment are extensively prone to various acute and chronic diseases, propelling high morbidity and mortality rates.
Intellectual abilities effectively determine knowledgebase competence and capacity. Approximately $52 \%$ of the world populace score between 90 to 100 on Intelligence Quotient. (6) Malnourishment confines children's cognitive capacity, dimensionally impair children score 8 to 18 points low on intelligence quotient then healthy mates. (15) Most African territories abide by starvation, stand among $24 \%$ executing score below 90 . (6)

8hrs./day and $48 \mathrm{hrs}$./week, the standard work capacity exercise globally. (7) Dividing GNI an economic metric, with average weekly working hours delineates the productivity. According to findings, 1\% increase in stature supplement $1.4 \%$ increase in productivity and 2 to $2.4 \%$ increase in prosperity. Malnourishment in early childhood comrades $12 \%$ reduce earning in later life span. (15)

Most Africa States exhibit GNI below \$1005 and execute $40 \mathrm{hrs}$. workload duration. $(3,7)$

Sufferers exhibit inordinate servility to psychological disarrays including stress, depression, anxiety, lags in behavioral attributes, easily arouse to anger and aggression. (28) Malnourished survivors likely to execute low performance, productivity, and proficiency in early and later phases of life.

Growth impairment instigates skeletal deformities, sufferer frequently encounters frailty, fracture, osteoporosis. (28) Additionally, reprehensible for the increased prevalence of diabetes, hypertension, cardiac disorder. (15) It also influences the reproductive system, increases the chances of menstrual disruption, premature deliveries, pre, and post-pregnancy complications. (15) Malnourishment considerably jeopardizes maternal and infant wellbeing. Study incorporating the analysis of 121 States reveals relatively negative relation of stunting and wasting with life expectancy, reportedly $\mathrm{r}=$ $0.67(\mathrm{p}<0.001)$ and $\mathrm{r}=-0.4(\mathrm{p}<0.001)(29)$

Inconsideration of the above-discussed challenges of malnourishment study proceeds with the exploration of healthy nutriments effectual in complying against stunting and wasting among children under age 5 .

The five selected the North African States, enduring similar ecology, less onerous with causation and consequences of malnourishment, demonstrate a relatively low prevalence of stunting and wasting than the rest of Africa. Consider States eminent in the production and consumption of salubrious nutrients, 
embracing dates, honey, olive oil, effective in children early age nurture and nourishment.

Beginning with dates, a salubrious intake often delineates as a complete diet, sustain high nutritional value, constitute mostly of carbohydrates, protein, vitamins, and mineral essential for one wellbeing. (30) Extensively grown in southern Asia, tropical and subtropical regions of Africa. Intimately 100 million palm trees are planted globally, produce 2.5 to 4 million tons of dates annually. Including 60 million palm trees in Asia and 32.5 million in Africa. (30) Egypt and Algeria stand among the top five producers.

Easily grown in underprivilege land masses characterize by extreme temperature, high humidity, and no rainfall. Requisite of conventional cultivation soil enrich nitrogen, phosphorus, potassium, boron, and appropriate spacing ensuring enough solar exposure. (30) These high energy boosters are highly beneficial for maternal health specifically during pre, and post parturition. Supplement infancy by ensuring regulation of the digestive system, mobilization of immunity, the functionality of the liver, acceleration of dimensional growth, production, and purification of blood. (31)

Honey an exuberant intake, extensively produce, and consume around the globe. According to the report, annually 1.6 million tons of honey is produced around the world, Asia stands eminent with significant contribution $46 \%$, followingly Europe $22 \%$, America $20 \%$, Africa $10 \%$, and least by Oceania $2 \%$.(32) Production of honey flourishes in natural ambiance, incorporating multi pollinated plant proffering honey bees poly floral diet enrich in protein, vitamin, minerals, fats, water by traveling small distances. (32)

In addition to an energizer, honey plays a significant role in children's early nourishment. Considerably contribute to catalyzing execution of cognitive and capacitive capabilities, amelioration of assimilation and retention ability, ensure availability of insulin and recuperation of muscles in case of injury. Endure exclusive feature of antiseptic, anticancer, and antioxidant. (33) A study incorporating 300 children of age under 5 indicates honey intake ensures sound sleep without disruption during nocturnal cough. Similarly, in an Egyptian study embracing children deficient of protein examined during nutrition rehabilitation program, 30 receive honey and 20 feed with placebo in addition to a nutritional diet. Outcomes reveal quick recovery and increase growth in group incorporate honey in the diet. The study also concludes honey a healthy substitute for white sugar. (34)

Finally, olive oil characterizing vitality, expedite neurological and physiological wellbeing. Estimated figures of 3.13 million tons reflect the olive oil global production, drive significantly by Spain, Italy, and Argentina whereas North African territories including Tunisia, Moscow, Algeria enjoy considerable shares. (35)

Olive trees are planted well in hot arid regions enduring intense temperature, comprise of dehydrated soil, Health benefits extend to large scale addresses various benign and malignant disarrays. Effectual in keeping vital organs and systems actuated. The incorporate proportion of omega 3 and omega 6 tantamount to breastfeed. Assist assimilation of Vit $d$, significant in bones ossification and regulation of body growth. (36)

The North African territories, among the main exporter of these healthy nutrients, also enjoy a flourishing economic profile.

\section{Conclusion}

Based on study findings internal and external mal exposures considerably reprehensible for continuous acclivity in the prevalence of stunting and wasting in Sub Sahara Africa. Moreover, populaces in Africa, with an increased proportion of malnourishment in early ages experience psychological and physiological health degeneration in later phases of life. However, North African territories, with similar ecology, execute populace salubrious and sustained profile, by producing and consuming healthy nutrients, effectually combats major causes and consequences of malnourishment than the rest of Africa.

\section{Reference}

1. FAO, IFAD, UNICEF, WFP and WHO. 2018. The State of Food Security and Nutrition in the World 2018.Building climate resilience for food security and nutrition. Rome, FAO. Available at: http://www.fao.org/3/I9553EN/i9553en.pdf

2. UNICEF ,WHO, 2019. Progress on household drinking water, sanitation and hygiene 2000-2017. Special focus on inequalities. New York. Available at: https://www.who.int/water_sanitation_health/public ations/jmp-2019-full-report.pdf?ua=1 
3. The World Bank,2017. World Bank Open Data. [Online] 2017 [Cited 2019 July 20]. Available at: https:/ / data.worldbank.org.

4. Weather-Atlas, 2019. Monthly weather forecast and Climate. Available at: https://www.weatheratlas.com/en

5. Nation Master,2013. Countries Compared by Environment $>$ Pollution perceptions $>$ Noise and light pollution. International Statistics at NationMaster.com. [Online] 2013 [Cited 2019 July 20] Available from: URL: http://www.nationmaster.com/countryinfo/stats/Env ironment/Pollution-perceptions/Noise-andlightpollution.

6. IQ research, 2019. World ranking of countries by their average. Available at: https:/ / iqresearch.info/en/page/average-iq-bycountry.

7. Nation Master, 2014. All countries compared for Labor $>$ Hours worked > Standard workweek".Available at: http://www.nationmaster.com/countryinfo/stats/Lab or/Hours-worked/Standard-workweek.

8. World Life Expectancy, 2019.Health Profile. Available at :http:/ / www.worldlifeexpectancy.com/

9. 2018 Global Nutrition Report: Shining a light to spur action on nutrition. Bristol, UK: Development Initiatives. Available at: https://globalnutritionreport.org/reports/globalnutrition-report-2018/

10. Onis, MD., Borghi, E., Arimond, M., Webb, P., Croft, T., Saha, K., et al.,2019. Prevalence thresholds for wasting, overweight and stunting in children under 5 years. PHN 2019; 22(1): 175-179.

11. Koletzko, B.,2008. Basic concepts in nutrition: Nutritional needs of children and adolescents. Clinical Nutrition ESPEN. 2008;3( 4): 179-84

12. Grebmer,KV., Bernstein,J.,Hammond,L., Patterson,F., Sonntag, A., Klaus,L., et al., 2018. 2018 Global Hunger Index: Forced Migration and Hunger. Bonn and Dublin: Welthungerhilfe and Concern Worldwide. Available at: https://reliefweb.int/sites/reliefweb.int/files/resource s/global_hunger_index_2018.pdf

13. Briend, A., Khara, T., Dolan, C., 2015.Wasting and stunting - similarities and differences:

Policy and programmatic implications. ENN 2015; 36( 1).

14. Amare,D., Negesse, A., Tsegaye, B., Assefa, B., Ayenie, B.,2016.Prevalence of Undernutrition and Its Associated Factors among Children below Five Years of Age in Bure Town, West Gojjam Zone, Amhara National Regional State, Northwest Ethiopia. APH; 2016.

15. Caulfield LE, Richard SA, Rivera JA, et al. Stunting, Wasting, and Micronutrient Deficiency Disorders. Disease Control Priorities in Developing Countries. 2nd edition. Washington (DC): The Oxford University Press, New York.
16. UNICEF, WHO, 2015. Progress on Sanitation and Drinking Water. Update and MDG Assessment. Available at:https://apps.who.int/iris/handle/10665/177752

17. Carrie Rickwood, C., Carr, GM.,2007. Global Drinking Water Quality Index Development and Sensitivity Analysis Report. Available at:https://wedocs.unep.org/bitstream/handle/20.500.1 1822/12214/gwqi.pdf?sequence=1\&amp \%3BisAllowed $=$

18. Vilcins, D., Sly, PD. and Jagals, P., 2018. Environmental Risk Factors Associated with Child Stunting: A Systematic Review of the Literature. Annals of Global Health 2018; 84(4):551-562.

19. Asadollahy MV, Keikha M, Poursafa P, Kelishadi R.,2018. A Systematic Review of the Effects of Environmental Pollutants, Chemical Factors, and Climate Changes on Children's Height, Health ScopeN2018; 7(4):e12864.

20. WHO,2005. WHO Air quality guidelines for particular matter, ozone, nitrogen dioxide and sulphur. Available at:https://apps.who.int/iris/bitstream/handle/10665/ 69477/WHO_SDE_PHE_OEH_06.02_eng.pdf?sequence $=1$

21. WHO, 2018. More than $90 \%$ of the world's children breathe toxic air every day.

News release. Available at: https:/ / www.who.int/news-room/detail/29-10-2018more-than-90-of-the-world \%E2\%80\%99s-childrenbreathe-toxic-air-every-day

22. WHO, 2002.Global solar uv index. Reportno: WHO/SDE/OEH/02.2,2002. Available at:https://apps.who.int/iris/bitstream/handle/10665/ 42459/9241590076.pdf?sequence=1\&isAllowed =y

23. Mokhtar, R., Holick, M., Sempértegui, F., Griffiths, J., Estrella, B., Moore, L., et al., 2018. Vitamin D status is associated with underweight and stunting in children aged 6-36 months residing in the Ecuadorian Andes. Public Health Nutrition 2018;21(11):1974-1985.

24. Nabeta, HW., Kasolo, J., Kiggundu, RK., Kiragga, AN., Kiguli, S. ,2015. Serum vitamin D status in children with protein-energy malnutrition admitted to a national referral hospital in Uganda. BMC research notes. 2015; 8: 418.

25. Bhat, M., Kalam, R., Qadri, SS., Madabushi, S., Ismail,A., 2013. Vitamin D Deficiency-Induced Muscle Wasting Occurs through the Ubiquitin Proteasome Pathway and Is Partially Corrected by Calcium in Male Rats, Endocrinology 2013;154(11): 4018-4029,

26. WHO.,1999.Guidelines for Community Noise . Available at: https://www.who.int/docstore/peh/noise/Comnoise4.pdf

27. Schell, LM., Gallo, MV., Denham, M., Ravenscroft, J.,2006. Effects of pollution on human growth and development: an introduction. JPA 2006; 25 (1): 103-12 . 
28. Stella, GU.,2016. Underweight, the Less Discussed Type of Unhealthy Weight and Its Implications: A Review. American Journal of Food Science and Nutrition Research 2016; 3( 5): 126-142.

29. Soheylizad, M., Ayubi, E., Mansori, K., Gholamaliee, B., Sani, M., Khazaei, S., et al.,2016. Human Development and related Components with Malnutrition in Children: A Global Ecological Study. International Journal of Pediatrics 2016; 4(8): 2299-2305.

30. Zaid, A. Date Palm Cultivation. Food and Agricultural Organization of The United Nations Rome, 2002. FAO Plant Production and Protection Paper 156 Rev. 1Available http://www.fao.org/3/y4360e/y4360e00.htm

31. Aparna, 2019.Giving Dates to Babies: Nutritional Value, Benefits and Precautions. Available at: https://parenting.firstcry

32. UNIDO,2015. Buckwheat Honey Market Study Final Report. https://open.unido.org/api/documents/4673719/dow nload/Buckwheat \%20Honey\%20Market\%20Study \%20F inal\%20Report

33. Nagdeve, M., 2019. 9 Surprising Benefits of Honey. Organic Facts. Available at : https://www.organicfacts.net/health-benefits/healthbenefits-of-honey.html

34. Ubesie, A., Ibeziakor, N. ,2012. High burden of proteinenergy malnutrition in Nigeria: beyond the health care setting. AMHSR 2012; 2(1): 66-69.

35. DAWSON, D., 2018.Global Olive Oil Production to Dip in 2018/19.Olive Oil Times. Available at: https://www.oliveoiltimes.com/business/global-oliveoil-production-to-dip-in-2018-19/66039

36. Parker,S, 2015.Filed in Health Olive Oil Works Wonders for Babies. Olive Oil Times. Available at: https://www.oliveoiltimes.com/health-news/olive-oilfor-baby/45502. 